\title{
A New Tape Product for Optical Data Storage
}

\author{
T. L. Larsen, F. E. Woodard, and S. J. Pace \\ Southwall Technologies Inc. \\ 1029 Corporation Way, Palo Alto, CA 94303 \\ Phone: 415-962-9111 \\ Fax: $415-967-8713$
}

\begin{abstract}
A new tape product has been developed for optical data storage. Laser data recording is based on hole or pit formation in a low melting metallic alloy system. The media structure, sputter deposition process, and media characteristics, including write sensitivity, error rates, wear resistance and archival storage, are discussed.

\section{Introduction}

Southwall Technologies, in cooperation with The Dow Chemical Company[1], has developed a new tape medla for optical recording (WORM type). The first product is designed for the CREO optical tape storage system, formatted for $35 \mathrm{~mm}$ and 1 terabyte per reel. The media has a broad wavelength responsivity and process adjustable reflectivity in the range of 40-75\%. In addition to serving current applications, the media shows significant promise for future, high-speed, high density, enclosed reel development, and may prove useful in other applications such as optical cards and flexible disks.
\end{abstract}

\section{Media Structure}

The media structure shown in Fig. 1 consists of three inorganic layers sequentially sputter deposited in a web coating vacuum system onto a PET substrate that has been pre-coated with organic type subbing and backcoat layers. The "optical metal" layer (oxygen doped) is based on the Dow Chemical patented alloy system $(\mathrm{Sn} / \mathrm{Bi} / \mathrm{Cu})$. The reactively sputtered "activation" layer (e.g., $\mathrm{ZrNx}$ ) provides protection and enhances sensitivity and hole formation during laser writing. The hard "abraslon" layer (e.g., $\mathrm{SiCHx}$, also reactively sputtered, acts as the primary protection against scratching and tape wear.

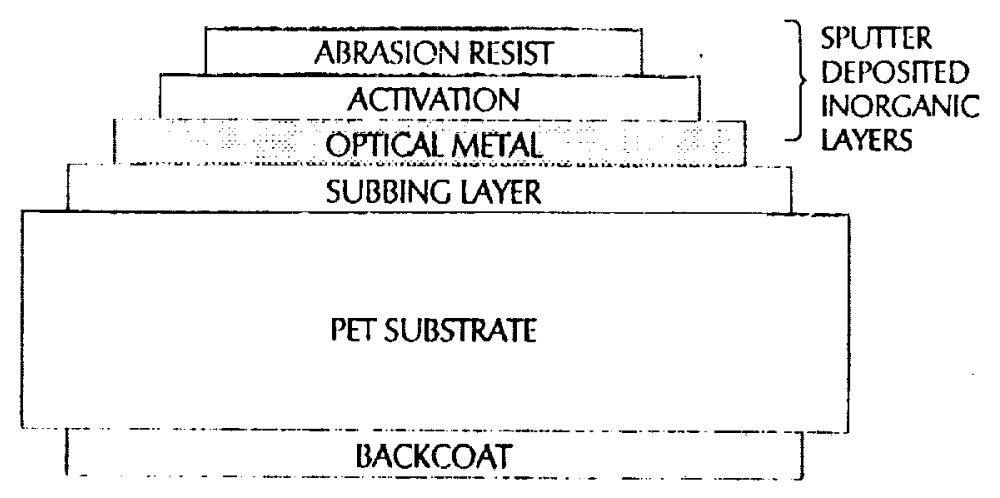

FIG.1: Structure of Optical Tape Media 
A proprietary process has been developed to "stabilize" the media against corrosion and phase separation observed previously in this alloy system under environmental testing at elevated temperatures and humidities. Although having the effect of decreasing the sensitivity of the media somewhat, excellent stability results have been demonstrated for this process, while still retaining sensitivity adequate for current applications. The subbing layer sets a smooth, hardened surface for the optical media and is particularly important in reducing optical defects in the PET surface. The backcoat enhances web or tape handling properties and can significantly reduce wear on the front surface of the tape.

\section{Vacuum Depostion}

A laboratory size sputtering machine (13" web width) is used with 3 separate minichambers located around the coating drum. Each minichamber is operated independently in either the metal or reactive sputtering mode for discrete and sequentlal layer depositions. Optical properties of the deposited layers are measured in-situ and used to computer control the operation. Optical monitors provide frequent wavelength scanning from $360-2200 \mathrm{~nm}$ of both reflection and transmission, and the computer provides down-web data logging of all process parameters. Typical optical properties of the media at two wavelengths are shown in Table 1.

TABLE 1: Optical reflection and transmission of medla at $670 / 830 \mathrm{~nm}$ on PET during sputter deposition.

\begin{tabular}{|l|c|c|c|}
\hline LAYER TYPE & THICK & म $(670 / 830)$ & (830) \\
\hline 1. Optical Metal Only & & $75 / 75 \%$ & $3 \%$ \\
2. With Oxygen Dopant & $\sim 35 \mathrm{nM}$ & $55 / 55 \%$ & $10 \%$ \\
3. With Activation Layer & $\sim 50 \mathrm{nM}$ & $43 / 50 \%$ & $8 \%$ \\
4. With Abrasion Layer & $\sim 65 n \mathrm{M}$ & $37 / 45 \%$ & $7 \%$ \\
\hline
\end{tabular}

\section{APEX WRITE/READ Test Results}

An APEX OHMT-300 instrument is used to measure recording characteristic with an $830 \mathrm{~nm}$ laser. For purposes of evaluation, modulation depth is defined as (RO-R1)/(RO. R2), where RO, R1 and R2 are reflectivities of unwritten media, written data bits and bare PET (typically 6\%), respectively. Full modulation (i.e., 1.0) is defined as the data bit reflection equal to base PET reflection. For the current product, modulation depth as a function of writing energy for various pulse widths is shown in Fig. 2 for two different lasers in the system, $10 \mathrm{~mW}$ and $50 \mathrm{~mW}$, and a disk rotation rate of $5 \mathrm{rps}$ (about $850 \mathrm{~mm} / \mathrm{s}$ velocity). Write sensitivity of the media increases substantially with decreasing pulse width. At the shortest pulse width tested $(50 \mathrm{~ns})$, full modulation is reached near $0.5 \mathrm{~nJ}$. The offset of the power curves at 250,300 and 350ns to lower energies (about $0.35 \mathrm{~nJ}$ ) for the $50 \mathrm{~mW}$ laser vs. the $10 \mathrm{~mW}$ laser is attributed to the spacial differences in the energy output of the two lasers incident on the media surface and/or a possible difference in calibration. 


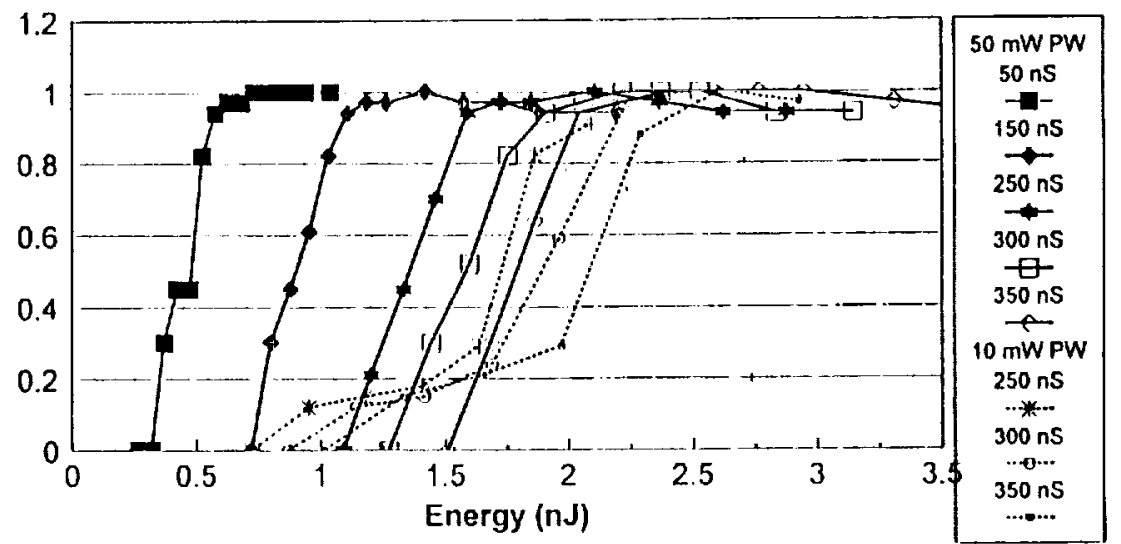

FIG.2: Modulation Depth vs. Writing Energy at Varlous Pulse Widths

The APEX test results (50mW laser) of writing energy as a function of pulse width at various fixed modulation depths are shown in Fig. 3 . Over the range tested, the writing energy $(P)$ at a fixed modulation depth decreases linearly with decreasing pulse width ( $t$ ) and can be described by the function, $\mathrm{P}=\mathrm{A}+\mathrm{Bt}$. At $50 \%$ modulationdepth, the intercept (A), at $t=0$ for an infinitely narrow pulse width, is $0.2 \mathrm{~nJ}$, and the slope (B) is $0.0045 \mathrm{~J} / \mathrm{s}$. The increase in writing energy for a fixed modulation depth is attributed to time dependent power dissipation by thermal conduction in the media. This characteristic implies a significant energy advantage (as well as speed) for shorter pulse writing.

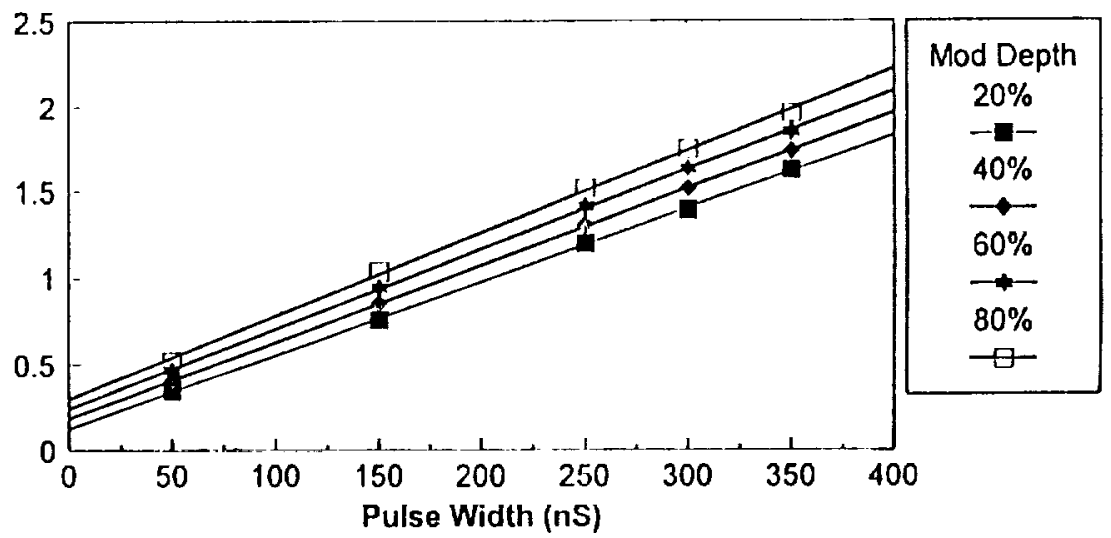

FIG. 3: Writing Energy vs. Pulse Width at Various Modulation Depths

\section{Data Bit Morphology}

CREO written data bits of approximately 1 micron diameter are shown on a section of tape in the photomicrograph of Fig.4. Formation of such data bits are shown in more detall by atomic force microscopy in the micrograph of Fig.5. With the exaggerated scaling in the $z$-axis, the bits appear as mounds with a somewhat faceted center pit. The cross-section of the lower bit in Fig. 5 shows the pit with a flat bottom, which may extend down to the substrate. The small rectangular features in the surface of the media are belleved to be metallic crystallites. 


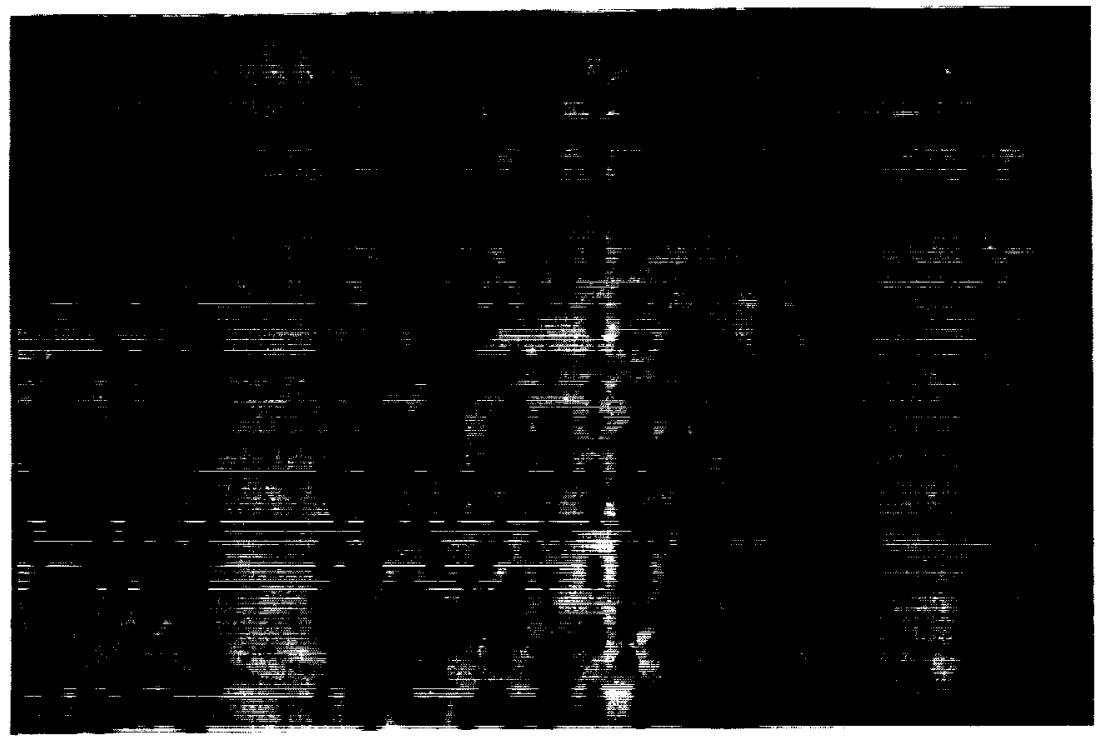

FIG. 4: Photomicrograph of CREO Written Tape

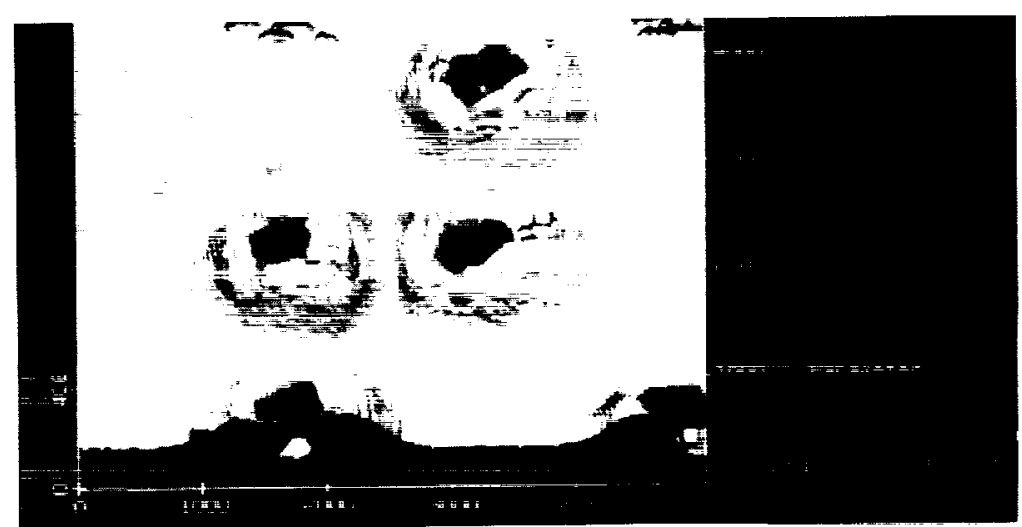

FIG. 5: AFM Micrograph of CREO Written Data Bit Scale $=\mathbf{n m}$

\section{Wear Test Results}

As a guide to developing wear resistance, a simple abrasion test with a hard eraser was employed to determine the number of strokes required to produce an observable removal of media from the substrate. The results in Table 2 indicate a major improvement in wear resistance for the combination of subbing and abrasion resist layers. The contribution of the subbing layer in enhancing abrasion resistance is attributed to a firmer base for the media provided by its hard-coat properties and stronger adhesion to the optical metal. The abrasion resist layer is then most effective under these conditions. There appears to be an optimal thickness of the abrasion resist layer, i.e., abrasion resistance improves significantly with increasing thickness, however, media sensitivity is somewhat diminished by thicker layers. Wear tests conducted at CREO on the optical tape recorder show very promising results. Initial (at zero search cycles) raw and corrected bit error rates are below $5 \times 10$ exp-5 and 10 exp-22, respectlvely. At search speeds of $5 \mathrm{~m} / \mathrm{s}$, more than 5,000 searches are readily obtained on tapes without backcoats before corrected bit error rates of $10 \mathrm{exp}-12$ are exceeded. With the current top side structure, the major contribution to wear appears to come from the back or slip-coated side of the tape. Very promising results have been obtained from samples with anti-abrasion back side coatings. 
TABLE 2: Simple Erasure Abrasion Resistance of Media Showing Effects of Subbing and Abrasion Resist Layers

\begin{tabular}{|c|c|c|}
\hline \multicolumn{3}{|c|}{ 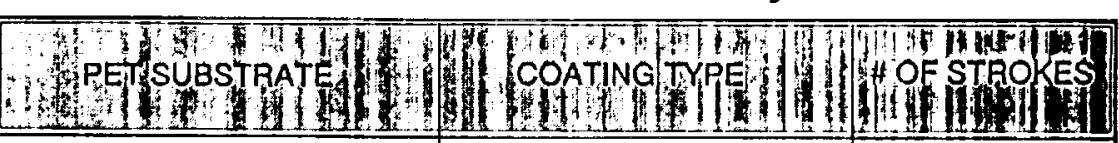 } \\
\hline \multirow{2}{*}{ WITHOUT SUBBING LAYER } & ACTIVATION LAYER ONLY & 7 \\
\hline & WITH ABRASION RESIST & 8 \\
\hline \multirow{2}{*}{ WITH SUBBING LAYER } & ACTIVATION LAYER ONLY & 12 \\
\hline & WITH ABRASION RESIST & 30 \\
\hline
\end{tabular}

\section{Environmental Test Results}

Accelerated aging tests were conducted by suspending unprotected tape strips in a temperature/humidity chamber at $70^{\circ} \mathrm{C}$ and $95 \% \mathrm{RH}$. Typical optical property changes with time for stabilized media are shown in Fig.6. Only slight changes in transmission and reflection were observed after 384 hours. At each test interval, the characteristics of modulation depth vs. writing energy were measured on the APEX tester (with the $10 \mathrm{~mW}$ laser and 250ns pulse width), as shown in Fig.7. No noticeable changes in writing characteristics were observed. All of these results are in sharp contrast to earlier experience with these media before the stabllization process was developed; i.e., the media would be totally degraded after weathering for 24 hours. Other tests are in progress to determine potential for 100 year archival life.

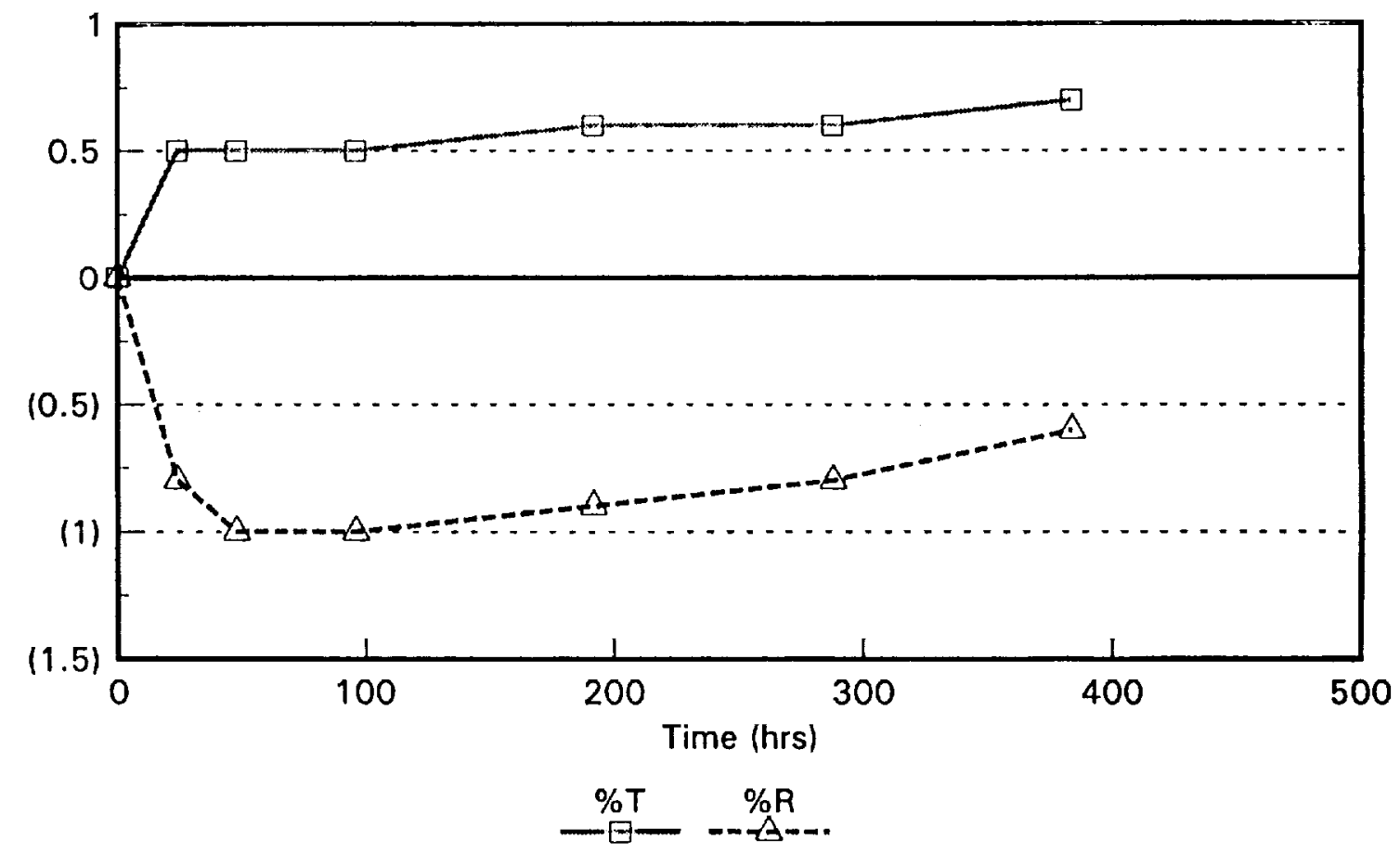

FIG.6: Change In Transmission \& Reflection vs. Time at $70^{\circ} \mathrm{C}$ and $95 \% \mathrm{RH}$ Change in Percent@850nm 


\section{Modulation Depth}

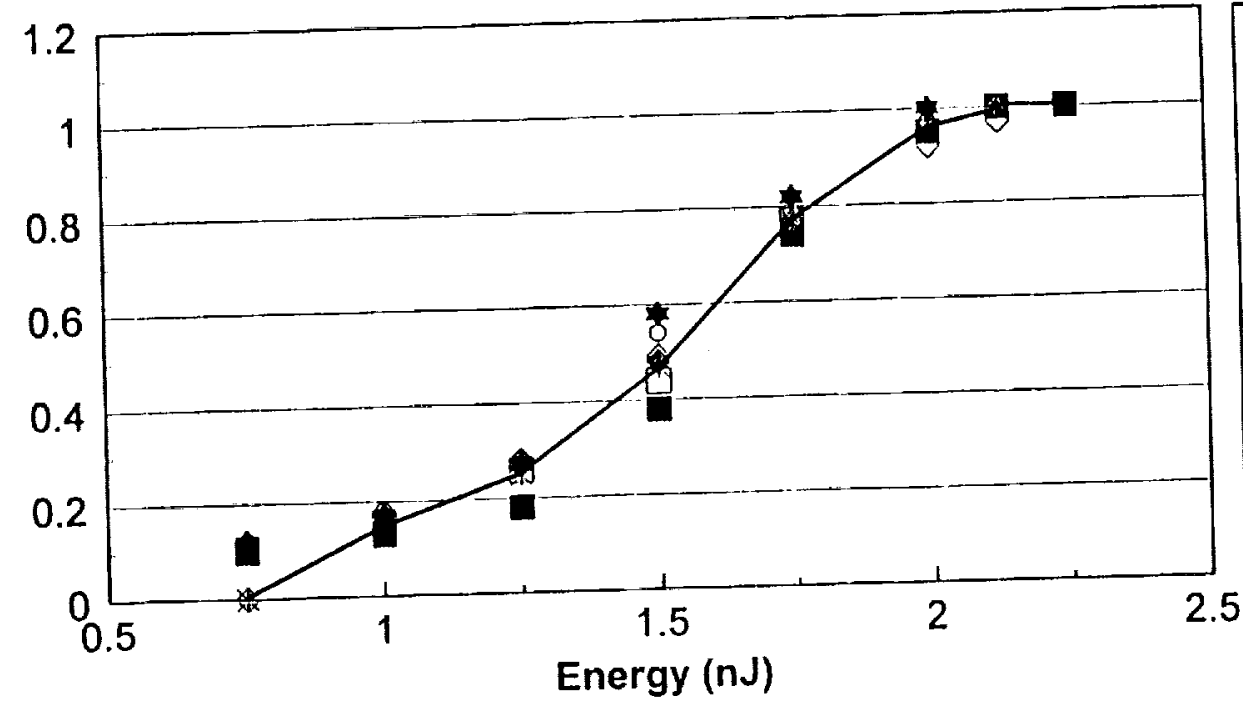

Exposure Time

$\mathrm{Ohr}$

$24 \mathrm{hrs}$

$\bullet$

$48 \mathrm{hrs}$

96 hrs

$192 \mathrm{hrs}$

$\diamond$

$288 \mathrm{hrs}$

*

$384 \mathrm{hrs}$

0

FIG. 7: Modulation Depth vs. Writing Energy at Various Times in $\mathrm{T} / \mathrm{H}$ Chamber at $70^{\circ} \mathrm{C}$ and $95 \% \mathrm{RH}$

\section{Conclusion}

An optical recording media has been developed for permanent digital storage application in tape formats. Useful characteristics of write sensitivity, durability and environmental stability have been demonstrated. The sputter coating process can be scaled to large, wide-web roll coaters for future high-volume production. Although tuning of overcoats will be required for blue lasers, the media is well suited for such developments in future higher speed, higher density applications.

\section{Acknowledgements}

For invaluable contributions and assistance, the authors thank D. Perettie, A. Strandjord, S. Webb and D. Hawn of Dow, D. Smythies of CREO and L. Peck and D. Willis of Southwall Technologies.

\section{References}

1. A.Strandjord, S.Webb, D.Beaman and S.Carroll, "Thin Film Coatings for Flexible Optical Data Storage", Proc. SPIE Optical Thin Films III: New Developments, San Diego, Vol. 1323, 1990. 